\title{
GBMR
}

\section{The Relationship Between Job Burnout and Job Satisfaction: Health Care Industry Perspectives}

\author{
Anisa Muhammad Nur1, Herman Shah Anuar2 \\ 1Othman Yeop Abdullah Graduate School of Business, Universiti Utara Malaysia, Malaysia \\ E-mail: anisamuhdnur@yahoo.com \\ ${ }_{2}$ Othman Yeop Abdullah Graduate School of Business, Universiti Utara Malaysia, Malaysia \\ E-mail: herman@uum.edu.my \\ 1Corresponding author: anisamuhdnur@yahoo.com
}

Received: January 142020 Revised: May 262020 Accepted: May 272020 Published: June 30 2020

\begin{abstract}
The healthcare industry is becoming one of the most growing concerns among people in Malaysia. This industry is expected to provide efficient and effective services to the community. This study is aimed to examine the relationship between the dimension job burnout, which includes emotional exhaustion, personal accomplishment, and depersonalization with job satisfaction among healthcare providers in the healthcare industry at the northern part of Malaysia. A quantitative methodology was applied in this study where 200 questionnaires had been distributed. Only 171 questionnaires were collected and returned back. Out of that number, only 156 questionnaires were fit to be analysed. It was found that all of the burnout dimensions (emotional exhaustion, depersonalization, and personal accomplishment) have a significant relationship to job satisfaction. Multiple Regression analyses have found that 2 of the independent variables had a negative relationship with job satisfaction (emotional exhaustion and depersonalization). Personal accomplishment is the most significant and had a strong relationship with job satisfaction. It is recommended for future research to conduct qualitative research to find diversity in the result, emphasising on other professions, including a firefighter, police officer, custom immigration officer, or any other enforcement profession which seems to have an issue with job burnout. It is challenging to conduct this research due to the geographical location since the location for this study is in the northern part of Malaysia. It involves many hospitals, clinics as well as patient-oriented personnel. On the other hand, future research may include a bigger number of medical and healthcare personnel all over Malaysia to get a better generalisation. A wider scope of the population will provide better findings that cover all spectrum of the healthcare provider.
\end{abstract}

Keywords: Healthcare provider, job burnout, emotional exhaustion, depersonalization, personal accomplishment and job satisfaction. 
Global Business Management Review, 2020

JUNE 2020

http://gbmr.oyagsb.uum.edu.my

\subsection{INTRODUCTION}

Recently, consumer's health trends are rapidly shifting. Consumers are proactively increasing their health-conscious lifestyles, concern about improving their healthcare by looking at what products they are consuming, which are the best brands or healthcare services that can help them to maintain their health. Undeniably, the health care sector is a continuously changing environment, with the working conditions are increasingly becoming more ultimatum and lots of pressure in hospitals (Portoghese, Rosa, Gabriele, \& Campagna, 2014). Akpinar, Tas, and Okur (2013) studied medical personnel including doctors, nurses in Kocaeli Province, and Turkey agreed that job satisfaction and emotional exhaustion have a strong effect on affective commitment.

Globally, the demand of healthcare now is gradually rising, which grows expectedly in the future due to the estimated demographic shifts, including the aging population, lifespan, and lifestyle diseases. Job burnout has the capability to create physical damage, psychological damage, which also lower down one's job efficiency, especially in difficult work conditions such as in the area health care services (Bazmi, Alipour, Yasamy, Kheradmand, Salehpour, Khodakarim, \& Soori, 2019).

The Malaysia Healthcare System is being developed and thanks to the pervasive support from the Malaysian government through investment in hospital medical infrastructure. Malaysia's healthcare system is classified into two health systems, known as public healthcare and a private healthcare system. During the unveiling 2019 Budget, the government gives the initiative to enhance the healthcare sector by proposed a large allocation of RM314.6bil for this sector, an increment of $8.3 \%$ from 2018 budget (The Star Online, 2018). This projection is in line with economic blueprints, whereas Malaysia's healthcare tourism has been recognised as one of the National Key Economics Areas (NKEA) a key indicator of nation development as well as a set of the drive toward achieving the status of the high-income nation by 2020 .

Despite all these economic growths, a bulk of empirical studies on burnout has promptly increased. It has been extensively conducted because it represented the quality of employee level of productivity and service delivery. Maslach, Schaufeli, and Leiter (2001) illustrated that burnout as 
Global Business Management Review, 2020

JUNE 2020

http://gbmr.oyagsb.uum.edu.my

the chronic fatigue syndrome, a cynical attitude, negative work attitude, and diminished the effectiveness of a professional that can be accomplished in any job.

When an individual encounters prolonged response to chronic interpersonal stressors on the job, he or she is considered to be facing a situation called "burnout". This psychological syndrome consists of three key categories, namely overwhelming exhaustion, feelings of cynicism and detachment from the job, and a sense of ineffectiveness and lack of accomplishment (Maslach, \& Leiter, 2016).

Most of the research on burnout goes further into the health professionals, including social workers, psychologists, physicians, and nurses (Leiter et al., 1994; Leiter \& Schaufeli., 1996), but some studies also cover the education sector and human resources professionals. However, not all the specific factors of one industry appear as factors in another sector. It may vary due to the work environment and working conditions.

\subsection{Problem Statement}

The Healthcare industry is regarded as one of the most stressful jobs in Malaysia (Jing, 2019) that leads to burnout, and it is crucial to be investigated because it represents a number of healthcare workers who have contributed a maximum job output as a patient life-saver. Moreover, working as healthcare provide their life with the high risk of contracting various types of illness (WHO, 2017), the material and legal demands of patients and their families when there is an indication of unjustifiable malpractice, is an undesirable prospect for those who is involved with health industry especially the new practitioner who has just begun work.

These jobs are stressful because of the rotating shifts and the stress of caring for critically ill patients, while they must maintain a positive attitude and attention to taking care of patients' even their selves fell the burden and stressful. So, the healthcare provider should not be burden with stress (Johnson, 1991). in order for them to deliver a high quality of service as they are dealing with patient feelings and pains. 
Global Business Management Review, 2020

JUNE 2020

http://gbmr.oyagsb.uum.edu.my

The healthcare industry is made up of many different types of healthcare providers, which is meant the individuals who provide medical care, healthcare assistance, and other treatment to patients. While most people are familiar with doctors and nurses, there are many other healthcare providers that assist in caring for patients and families. This study will focus on medical-related professions such as doctors, registered staff, the health patients' assistance, and also the administrator.

According to Van Mol (2015), healthcare employees are often exposed to the enormous emotional burden that resulted from families of suffering and the pain patients, whereby they need to pretend calm emotionally. The effect from the long term pressure can affect individuals' personal achievements and their psychological aspects, which can lead to a tendency of drug usage, alcoholic, or consumption of illegal drugs to alleviate the symptoms (Ullström et al., 2014)

State Audit Report 2018 Series 1 on the Ministry of Health Malaysia quoted that the Department of Emergency and Trauma (ETD) has experienced a shortage of workers due to the number of patient visits exceeding the "Level of Care" which ranges from 5.7 to 95.6 percent. The report also cited the shortage of care for emergency specialists ranging from 75.6 to 79.5 percent, medical personnel between 41.2 to 64.6 percent, assistant medical staff between 2.6 to 33.9 percent and trained nurses between 17.4 to 67.1 percent (BERNAMA, 2019), this shortage may be linked to unrealistic workload that brought a lot of stress to the healthcare provider in order for them to meet the number of patients' demand.

In addition, the healthcare workers have long been known to be highly depressed and are associated with higher levels of psychological stress than other employees from different sector (Piko, 2006). In April 2012, Malaysia was shocked by the news that a trainee was found dead in a bathroom at Kajang Hospital. A used syringe was found next to the deceased; which police believed, he used it to inject drugs to fight off fatigue. Victim had been working on call for five consecutive days without off days for average 60 hours (The Star, 2012). The high work demands caused this kind of worst thing happen. The tendency of lack of well-being in their daily lives may result in job dissatisfaction, and finally having a poor quality of life.

The Guardian UK found that the increasing of long hour shifts are actually impairs pressure caused by employee shortage. In 2014, estimated 1,500 nurses in London were diagnosed with stress and 
Global Business Management Review, 2020

JUNE 2020

http://gbmr.oyagsb.uum.edu.my

fatigue. Some said that their level of depression and anxiety increased because of the stress they face at work (Kirk, 2015). It is obviously seen that most of the healthcare provider suffer from chronic work stress that leads to burnout as the challenges and burdens faced by them is increasing year by year. In addition, there is evidence outline fatigued faced among nurses in Singapore until they did not have time break for having lunch. Even though the Labour Act clearly stated that every worker is entitled to have a 1-hour break. This is due to nurses need to take care of a huge number of patients daily (Farhan, 2015).

Despite these interesting findings on the employee job burnout, very limited studies have validated and has not been empirically investigated the job burnout model across countries where work values and culture are different. Even though studies have been conducted in diverse field industries such as health industry, educational and professional fields to investigate the relationship of job burnout and job satisfaction due to the negative impact on organizations as well as the personnel itself. However, studies on job burnout in the healthcare industry, especially in the selected region, are still limited.

To conclude, the utmost importance of employee satisfaction is to ensure the issue of job burnout are controlled especially work-related pressure that can lead to burnout, if employee level of burnout increase, significantly it will increase employee turnover intention due to low satisfaction in performing their tasks. The high number of turnover may affect the organization's revenue and profitability as well as lower productivity due to the loss of quality and knowledgeable employees. The objective of the study are:

To determine there is a relationship between emotional exhaustion and job satisfaction To examine if there is a relationship between depersonalization and job satisfaction

To determine the relationship between personal accomplishment and job satisfaction

To evaluate if there is a relationship between all burnout dimensions and job satisfaction

The present study is aimed to provide readers broad, comprehensive perspectives and identifying the job burnout and job satisfaction level among healthcare providers. This study will focus on the healthcare institutions in the district of Kangar, Perlis, and Alor Setar, Kedah. First and foremost, the relationship between variables of job burnout and job satisfaction should be a focus in and it 
Global Business Management Review, 2020

JUNE 2020

http://gbmr.oyagsb.uum.edu.my

should be examined in order for an organization to find out the solutions in preventing burnout as well as raise job satisfaction level. As known that may factor will lead to job satisfaction, burnout is considered an important factor as it leads to mental and physical exhaustion, feelings of shrink from work, sleep problem, depression, and fatigue. This situation may cause the healthcare provider to withdraw from the patients. The previous literature mostly examines and concerned about the stress at work, job characteristics, or often burnout and satisfaction.

However, the majority of the studies conducted were frequently focused in the big city. This study is unique since the focus are in the suburban area in the northern region of Malaysia. According to Maslach et al.; (1996), the study found that if burnout is high, employee job satisfaction will decrease and in the meantime, the level of job turnover and absenteeism in the organization also increases. The study of job satisfaction among emergency health professionals conducted by Tarcan (2017) showed that the dimension of burnout, which is emotional exhaustion is a significant variable that affects job satisfaction.

Since the healthcare provider was considered a highly stressful job and the pressure on the quality of services, they able to provide can below. The utmost is to determine the burnout level among the healthcare provider, so that, a health institute can be aware of the root caused and come out with the initiative to alleviate it by providing a positive work setting environment. A positive working environment able to create a positive feeling among the employee to come to works and motivated them to sustain throughout the day. By conducting this study, hopefully, this could help the readers gain a understand more on the healthcare provider responsibility that is expected to be burnout and their level of job satisfaction, and identifying other variables that cause burnout in Malaysia's healthcare as well as improving the efficiency and effectiveness of healthcare providers' performance.

\subsection{Literature Review}

Over the years, job burnout has been a constant concern for both employees and an organization. Numbers of literature been conducted to have an explanation and understanding of the possible factors and impact of burnout towards organizational and personnel. Vast numbers of previous 
Global Business Management Review, 2020

JUNE 2020

http://gbmr.oyagsb.uum.edu.my

studies have evaluated the significant relationship between job burnout and job satisfaction among workplace workers. Chan, Wan, \& Kuok, (2015) mentioned that workers either working in the private or public sectors face excessive pressure in their jobs because there are required to perform various of jobs. Moreover, bulk of studies has stressed out profession which involve close personal contact with people are exposed to the hazards of emotional stress and exhaustion, that due to the high work demand and their responsibilities, extended hours of work and other factors, making the healthcare provider's profession in top cart of the stressful jobs that leads to possible burnout.

\section{Job Satisfaction}

It can be conceptualized as the pleasurable emotional state resulting from the appraisal of one's job as achieving or facilitating the achievement of one's job values (Locke, 1969). Job satisfaction is widely recognized as beneficial for organizations because it is generally associated with positive work outcomes such as low turnover and high organizational commitment. Aziri (2011) mentioned that, employees' level of job satisfaction can range from extreme satisfaction to extreme dissatisfaction. Besides attitudinal effects towards their jobs as a whole, there are other aspects which also play pivotal role to job satisfaction, such as the type of work they do, co-workers, supervisors or subordinates and remuneration (George \& Jones, 2008). According to Akpinar, et. al (2013), by increasing job satisfaction and decreasing emotional exhaustion of emergency services employees, it would improve their affective commitment to their organizations.

Job satisfaction is the most widely researched job attitude and among the most extensively researched subjects in Industrial/Organizational Psychology (Judge \& Church, 2000). On other hand, Meyer, Allen, \& Smith (1993) define job satisfaction as evaluative judgments employees hold toward their occupational duties is important because it has strong implications for attendance, turnover, sabotage, job performance, and the mental and physical health of employees (Miao, Humphrey, \& Qian, 2016).

Besides that, studies also indicate that employees exhibit higher level of job satisfaction when they are exposed to less stressful working environments (Pillay, 2009). Therefore, it is mandatory to investigate the relationship between job burnout and job satisfaction in single study. Since the call 
Global Business Management Review, 2020

JUNE 2020

http://gbmr.oyagsb.uum.edu.my

operator tasks can be classified into complex and demanding, it is a must for them to deal with various characteristics of personality and complexity.

Job satisfaction was found had significant negative effects on each of the three burnout measures (emotional burnout, depersonalization, and personal accomplishment). It makes sense that being passionate to your job may result in reduced emotional exhaustion (Lambert, Qureshi, Frank, Klahm, \& Smith,2018). Tourigny, Baba, \& Wang, (2010), found that the chronic experience of burnout tends to increase depression and other health-related problems.

\section{Job Burnout}

It is considered as an "occupational phenomenon", one of the category mentioned under International Classification of Diseases (WHO, 2019). Baldwin, Barmore, Suprina, \& Weaver (2011), highlighted that burnout is a job stress phenomenon and is also a form of mental distress that may be accompanied by physical health issues (Wardle \& Mayorga, 2016).

It is a negative psychological state experienced by people when they are exposed to stress for long periods of time. Burnout is different from stress in that burnout is deliberated as a prolonged presence of stress (Mäkikangas \& Kinnunen, 2016) and is distinguished from depression in terms of domain (Maslach et al., 1996).

Maslach (2003) has identified several causes that have been known to lead to burnout. These include work overload, lack of control, unsupportive work peers, and punitive supervisors. All of these issues can lead to an increase in the risk of or hastening burnout (Wardle \& Mayorga, 2016).

Once burnout has occurred, the potential for disruption in a person's life in the area of physical, psychological, and emotional health increases in a negative direction (Morse, Salyers, Rollins, Monroe-DeVita, \& Pfahler, 2012). In addition, burnout has been associated with physical and mental health issue such as physical exhaustion, insomnia, alcoholic, drug abuse, family problems, depression, anxiety, headaches, backaches, and gastric intestinal problems (Burke \& Richardsen, 1996; Maslach, Jackson and Leiter, 1996).

\section{Emotional exhaustion}


Global Business Management Review, 2020

JUNE 2020

http://gbmr.oyagsb.uum.edu.my

Emotional exhaustion is the most important dimension of burnout. It represents a feeling of energy loss and a sense of being completely drained out of emotional and physical strength (Nagar, 2012). It can be characterised by feelings of emotional depletion, extreme tiredness, a lack of energy and a feeling of being drained of emotional resources to cope with continuing demands (Cordes \& Dougherty, 1993; Maslach et al., 2001).

From another point of view, emotional exhaustion is refer to a chronic state of physical and emotional depletion that results from excessive job demands and continuous hassles (Wright \& Cropanzano, 1998). Employees who experience this problem tend to feel emotionally overwhelmed and worn out especially when they face workloads that require significant amounts of time and energy to perform (Hur et al., 2014).

\section{Depersonalization}

Depersonalization or derealization disorder is a condition that indicates an overlooked, common, and debilitating dissociative condition. The primary core features include persistent or recurrent depersonalization and/or derealization, such as profound sensations of unreality and detachment. It also refers to "an impersonal and dehumanized perception of recipients, characterized by a callous, negative, and detached attitude" (Salanova et al., 2005). The tendency to occur when employees adopt dysfunctional coping strategies to deal with stress at work. It may happen when employees perceive a lack of control over key aspects of their job (Maslach \& Jackson, 1981). People who encounter depersonalization tend to stay away from others.

\section{Diminished Personal Accomplishment}

It is defined as a decline in one's feeling of competence and successful achievement in one's work (Janssen et al., 1999). It happens when employees feel lacks the confidence to perform their work effectively and normally it will develop when employees feel their efforts are not equal with the expected result or not being appreciated or recognized by the employer.

In the United States of America, Lancet (2017) found that 400 doctors led suicides have been recorded. This situation has raised serious concern among the organization. Therefore, several organizations are united to expose this scenario within the working industry circle, with the aim 
Global Business Management Review, 2020

JUNE 2020

http://gbmr.oyagsb.uum.edu.my

of allowing intervention. For the past four years, Malaysia police statistic indicated more than 500 people commit suicide or have a tendency to attempt suicide every year. According to the Deputy Director of Criminal Investigation Department, Datuk Mohd Zakaria Ahmad said that between 2014 until February 2018, a total of 1,696 people were reported committing suicides, while 625 attempted suicide but failed to end their lives. Most of the reasons were financial problems, workrelated stress, family and relationship problems, and also studies (NST, 2018).

Although broad literature on job burnout and job satisfaction among professional workers in the health sector have been conducted studies. To the date, there is still a limited number of studies focus on the relationship between burnout and job satisfaction among healthcare providers that consist with a group of occupations such as doctors, registered staff, the health patients' assistance and also the administrator. Most of the studies have been conducted in the busiest city like Kuala Lumpur and Penang, so it is a good chance for present research to analyse and focus with the northern region, especially in Perlis and Kedah how this burnout tendency related with their job performance and satisfaction.

In this context, a regular assessment of the situation and the investigation of job satisfaction job burnout should be conducted and evaluated. The employees who are involved with the health industry, either in public or private hospitals carries many roles and responsibilities that contribute towards the patient's treatment plan. Therefore, it is important for a worker who is working in this field are well qualified. Thus, it is important that the worker does not get burnout so they can deliver the services, and contributions to patients are equally effective.

Present study examines dimensions of burnouts and job satisfaction level among the occupation group likely doctors, nurses, patient assistance service and administrator, whose works for health services in northern region Malaysia health system. Burnout can be an extra cost for organizations such as absenteeism, lack of motivation to perform their tasks. Some may lead to serious matters like mental disorder and also hospitalization. Hence, important for an organization to prevent this to happen by gained employee trust and beliefs. Organizations should have a clear goal and objective, understand employee needs, and try to provide it to ensure that they feel satisfied with their work. 
Global Business Management Review, 2020

JUNE 2020

http://gbmr.oyagsb.uum.edu.my

This study seeks to test the following hypotheses:

a. H1-There is a positive relationship between emotional exhaustion and job satisfaction.

b. H2-There is a positive relationship between depersonalization and job satisfaction.

c. H3- There is a positive relationship between personal accomplishment and job satisfaction.

d. H4- There is a relationship between all burnout dimensions and job satisfaction.

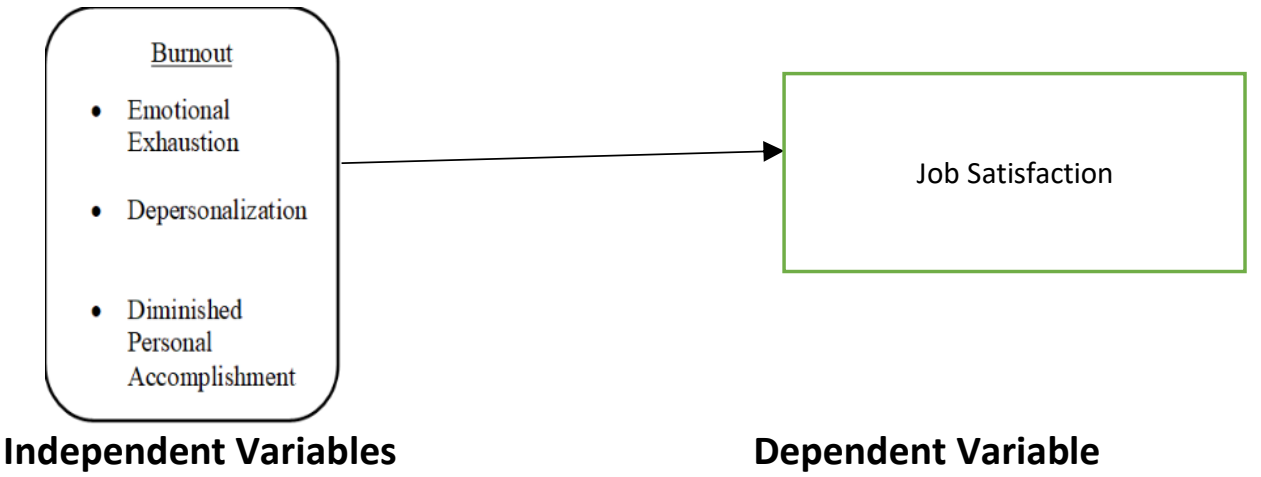

\subsection{Research Methodology}

A quantitative approach is applied in this study. Respondents for this study were among healthcare providers in four different hospitals, including Public and Private hospital, which is based in Kangar, Perlis, and Alor Setar, Kedah. According to Krejcie and Morgan (1970), for the 3000 population, the sample size needed is 379 . Half of 379 questionnaires were distributed. From the survey questionnaires were distributed, only 171 survey questionnaires were returned. Valid responses that were fit to be analysed were only 156 questionnaires.

156 out of 171 responses collected, it indicates a $41.1 \%$ response rate. The respondents were selected amongst those who work directly or indirectly in the medical health profession, including doctors, nurses, and other healthcare personnel. The questionnaire was distributed within a month, starting from October 182019 until November 16 2019. The age range of the respondents is from below 20 years old until up to 51 years old. 
Global Business Management Review, 2020

JUNE 2020

http://gbmr.oyagsb.uum.edu.my

The measure of job burnout was adopted from the Maslach Burnout Inventory General Survey (Schaufeli et al., 1996). The scale consists of sixteen items which are divided into f items related to emotional exhaustion, five items related to depersonalization, and six items related to perceived lack of personal accomplishment. All items will be measured on a five-point Likert scale, ranging from 1 (Strongly disagree) to 5 (Strongly Agree).

Job Satisfaction Scale developed by Kuzgun et al. 's (1999) consist of 20 items. These items will be measured on a five-point rating scale, ranging from 1 (Very Dissatisfied) to 5 (Very Satisfied). The JSS scale was developed and validated using Factor Analysis to assess the construct validity of the scale, which was found to have a two-factor solution, with the first factor explaining $36.4 \%$ of the total variance, and the second, 12.2\% (Kuzgun and Bacanl1 2005). The scale also can be used as a one-dimensional scale. The instrument's Cronbach's alpha internal-consistency coefficient was .90 (Kuzgun \& Bacanlı 2006; Kuzgun et al. 1999).

\subsection{Analysis and Findings}

To test these hypothesis, questionnaires were sent to all 189 employees (medical doctors, nurses and other health care personnel) in emergency services of public hospitals in northern region of Malaysia. The data obtained from this study were evaluated by using SPSS v22.0. 156 questionnaires were returned to the researchers representing a response rate of $41.1 \%$. Table 4.1 indicates the demographic statistic.

Table 4.1: Demographic Statistic

\begin{tabular}{lrr}
\hline & Frequency & Percent \\
\hline Gender & & \\
Male & 20 & 12.8 \\
Female & 136 & 87.2 \\
Total & 156 & 100.0 \\
Age Group & & \\
$<21$ years old & 6 & 3.8 \\
$21-30$ years old & 84 & 53.8 \\
$31-40$ years old & 54 & 34.6 \\
$41-50$ years old & 7 & 4.5 \\
$>51$ years old & 5 & 3.2 \\
Total & 156 & 100.0 \\
\hline
\end{tabular}


Global Business Management Review, 2020

JUNE 2020

http://gbmr.oyagsb.uum.edu.my

\begin{tabular}{lrr}
\hline Occupation Group & & \\
Doctor & 22 & 14.1 \\
Nurse & 96 & 61.5 \\
Administrator & 22 & 14.1 \\
Patient Service Assistant & 16 & 10.3 \\
Total & 156 & 100.0 \\
Average Working Hours & & \\
$<8$ hours & 22 & 14.1 \\
$8-12$ hours & 118 & 75.6 \\
$>12$ hours & 16 & 10.3 \\
Total & 156 & 100.0 \\
Length of Employment & & \\
$<1$ years & 8 & 5.1 \\
$1-3$ years & 29 & 18.6 \\
$4-6$ years & 50 & 32.1 \\
$7-9$ years & 41 & 26.3 \\
$>9$ years & 28 & 17.9 \\
Total & 156 & 100.0 \\
\hline
\end{tabular}

The gender distribution was $12.8 \%$ male and $87.2 \%$ female. $61.5 \%$ of respondents are nurses, $14.1 \%$ are doctors, $14.1 \%$ are administrative staff, and $10.3 \%$ patient service assistant. Respondents working hour round between 8-12 hours scored 75.6\%, below 8 hour working per day is $14.1 \%$, and $10.3 \%$ works up to 12 hours a day. $53.8 \%$ are in the range of $21-30$ years old, $34.6 \%$ in the range $31-40$ years old, 3.8\% aged less than 21 years old, $4.5 \%$ in the range $41-50$ years old, and finally, $3.2 \%$ in the range 51 years old and above.

The majority of respondents show that they have been working for the selected hospital for more than 4-6 years $(32.1 \%)$. The percentage of respondents who are working around 7-9 years was $26.3 \%$, with a total of respondent 41 . The rest of them followed by within $1-3$ years $18.6 \%$, working more than nine years was $17.9 \%$, and below one year was $5.1 \%$ only.

Cronbach's alpha is as an indicator to check the degree of consistency for this study. The variables of job satisfaction and the three dimension of burnout (emotional exhaustion, personal accomplishment, and depersonalization) were tested using this method to determine the internal consistency. The following table shows the results of the reliability test for this study.

Table 4.2: Reliability Test Result 
Global Business Management Review, 2020

JUNE 2020

http://gbmr.oyagsb.uum.edu.my

\begin{tabular}{llcc}
\hline \multicolumn{1}{c}{ Variables } & \multicolumn{1}{c}{ Dimension } & Cronbach's Alpha & No. of item \\
\hline Independent & Emotional Exhaustion (EE) & 0.734 & 5 \\
Variables & Personal Accomplishment (PA) & 0.386 & 5 \\
& Depersonalization (DP) & 0.775 & 5 \\
Dependent Variable & Job Satisfaction (JS) & 0.703 & 7 \\
\hline
\end{tabular}

Table 4.2 showed that the reliability values for three independent variables and one dependent variable. The value of Cronbach's alpha for the independent variables, namely emotional exhaustion was 0.734 , for depersonalization was 0.775 and for personal accomplishment was 0.386. A low value of alpha could be due to a low number of questions, poor inter-relatedness between items, or heterogeneous constructs. In this case, Personal Accomplishment (PA) is low due to poor correlation between items.

For the dependent variable, job satisfaction, the Cronbach's Alpha value was 0.703. According to the reliability value of Cronbach's alpha, the value of emotional exhaustion, depersonalization and job satisfaction indicated the measuring items have a good reliability. Nonetheless, personal accomplishment reliability value was indicated below than 0.60 , which is means poor reliability in measuring items according to Cronbach's Alpha. For this study, the correlation of variables was exhibited using the Pearson correlation coefficient, while linear regression was used to present the summary results of this analysis.

\subsection{Pearson Correlation Coefficient Analysis}

The strength of the relationship can be determined by the Pearson correlation $(r)$. When the $r$ value is 0 , it means that there is no relationship between two variables was indicated, and if the r value is 1 , it shows that there is a positive correlation relationship between two variables. However, if the $\mathrm{r}$-value is -1 , it explained that the relationship between the two variables is negatively correlated.

\subsubsection{Emotional Exhaustion and Job Satisfaction}

H1: There is a significant relationship between emotional exhaustion and job satisfaction.

Table 4.3: Correlations between Emotional Exhaustion and Job Satisfaction Job Satisfaction

Pearson Correlation

$-.379^{* *}$


Global Business Management Review, 2020

JUNE 2020

http://gbmr.oyagsb.uum.edu.my

\begin{tabular}{llll} 
Emotional & Sig. (2-tailed) & & .000 \\
Exhaustion & $\mathrm{N}$ & 156 & 156 \\
& Pearson Correlation & $-.379^{* *}$ & 1 \\
& Sig. (2-tailed) & .000 & \\
& $\mathrm{~N}$ & 156 & 156 \\
\hline
\end{tabular}

Based on the result above show that the emotional exhaustion and job satisfaction has a negative correlation. The value correlation indicates -0.379 between emotional exhaustion and job satisfaction. Thus, when the emotional exhaustion is high, job satisfaction is low and vice versa. There is a weak relationship between emotional exhaustion and job satisfaction $(\mathrm{r}=-0.379 ; \mathrm{p}<$ 0.001). The correlation for these 2 variables is significant because the $p<0.001$. Therefore, hypothesis $(\mathrm{H} 1)$ is accepted.

\subsubsection{Depersonalization and Job Satisfaction}

$\mathrm{H} 2$ : There is a significant relationship between depersonalization and job satisfaction.

Table 4.4: Correlations between Depersonalization and Job Satisfaction

\begin{tabular}{llll}
\hline & & Job Satisfaction \\
\hline Depersonalization & Pearson Correlation & 1 & $-.540^{* *}$ \\
& Sig. (2-tailed) & & .000 \\
N & 156 & 156 \\
& Pearson Correlation & $-.540^{* *}$ & 1 \\
Sig. (2-tailed) & .000 & \\
$\mathrm{~N}$ & 156 & 156 \\
\hline
\end{tabular}

Based on the result above show that the depersonalization and job satisfaction has a negative correlation. The value correlation indicates, -0.540 between depersonalization and job satisfaction. Thus, when the depersonalization is high, the job satisfaction is low and vice versa. There is a strong relationship between depersonalization and job satisfaction $(\mathrm{r}=-0.540 ; \mathrm{p}<0.001)$. The correlation for these 2 variables are significant because the $\mathrm{p}<0.01$. Therefore, hypothesis (H2) is accepted.

\subsubsection{Personal Accomplishment and Job Satisfaction}

H3: There is a significant relationship between personal accomplishment and job satisfaction.

Table 4.5: Correlation between Personal Accomplishment and Job Satisfaction

Job Satisfaction 
Global Business Management Review, 2020

JUNE 2020

http://gbmr.oyagsb.uum.edu.my

\begin{tabular}{llll}
\hline Personal & Pearson Correlation & 1 & $.381^{* *}$ \\
Accomplishment & Sig. (2-tailed) & & .000 \\
& N & 156 & 156 \\
& Pearson Correlation & $.381^{* *}$ & 1 \\
& Sig. (2-tailed) & .000 & \\
& N & 156 & 156 \\
\hline
\end{tabular}

Based on the result above show that personal accomplishment and job satisfaction has positive correlation. The $r$-value indicates 0.381 between emotional exhaustion and job satisfaction. Thus, if the personal accomplishment is high, job satisfaction is also high and vice versa. There is a strong relationship between personal accomplishment and job satisfaction $(\mathrm{r}=0.381 ; \mathrm{p}<0.001)$. The correlation for these 2 variables is significant because the $\mathrm{p}<0.01$. Therefore, hypothesis (H3) is accepted.

This multiple regression analysis was used to test the relationship between these two variables, and the results will show each of the independent variables' strength of relationship towards the dependent variable and also the contribution weight.

Ho: There is no significant relationship between the three dimensions of job burnout (emotional exhaustion, personal accomplishment, and depersonalization) and job satisfaction.

H1: There is a significant relationship between the three dimensions of job burnout (emotional exhaustion, personal accomplishment and depersonalization) and job satisfaction.

Table 4.5: Multiple Regression Analysis (Model Summary)

\begin{tabular}{llllll}
\hline $\begin{array}{l}\text { Model Summary } \\
\text { Model }\end{array}$ & R & R Square & $\begin{array}{l}\text { Adjusted } \\
\text { R Square }\end{array}$ & \multicolumn{2}{l}{$\begin{array}{l}\text { Std. Error of theChange Statistics } \\
\text { Estimate }\end{array}$} \\
\hline 1 & $.619^{\mathrm{a}}$ & .383 & .370 & .67487 & .383 \\
\hline
\end{tabular}

According to the table result above, $\mathrm{R}$ Square value is 0.383 , and after minus the error, the accurate adjusted $\mathrm{R}$-the square is 0.370 , which is means $37 \%$ of job satisfaction (dependent variable) can be explained by independent variables (emotional exhaustion, personal accomplishment and depersonalization).

Table 4.6: Analysis of Variance (ANOVA ${ }^{\mathrm{a}}$ )

\begin{tabular}{|c|c|c|c|c|c|c|}
\hline \multicolumn{2}{|c|}{ Model } & Sum of Squares & Df & Mean Square & $\mathrm{F}$ & Sig. \\
\hline \multirow{3}{*}{1} & Regression & 42.899 & 3 & 14.300 & 31.397 & $.000^{\mathrm{b}}$ \\
\hline & Residual & 69.228 & 152 & .455 & & \\
\hline & Total & 112.127 & 155 & & & \\
\hline
\end{tabular}


Global Business Management Review, 2020

JUNE 2020

http://gbmr.oyagsb.uum.edu.my
a. Dependent Variable: MEANJS
b. Predictors: (Constant), MEANDP $=$ Depersonalization, MEANPA $=$ Personal
Accomplishment, $\quad$ MEANEE = Emotional Exhaustion

Findings indicated from table 4.4 shows that, the $\mathrm{F}$ ratio $(31.397)$ is significant. The $\mathrm{P}$ values $<$ 0.001 which is less than the significant level standard 0.05 . Therefore, can conclude that there is highly significant relationship between burnout dimensions (emotional exhaustion, personal accomplishment and depersonalization) in term of its job satisfaction. Besides, the $\mathrm{H} 1$ is supported.

Table 4.7: Results of Multiple Regression Analysis (Parameter Model)

\begin{tabular}{|cl|l|l|l|l|l|}
\hline \multirow{2}{*}{ Model } & \multicolumn{2}{|l|}{ Unstandardized Coefficients } & $\begin{array}{l}\text { Standardized } \\
\text { Coefficients }\end{array}$ & \multirow{2}{*}{ Sig. } \\
\cline { 2 - 5 } & & B & Std. Error & Beta & & \\
\hline \multirow{3}{*}{1} & (Constant) & 3.855 & .502 & & 7.678 & .000 \\
& MEANEE & -.286 & .085 & -.239 & -3.351 & .001 \\
& MEANPA & .426 & .109 & .268 & 3.898 & .000 \\
& MEANDP & -.351 & .076 & -.351 & -4.632 & .000 \\
\hline
\end{tabular}

\section{Dependent Variable: MEANJS}

Table 4.7 indicated that the $b$ values estimation and these value could measure the strength each predictor variable influence the principle of the dependent variable. In this study, $b$ values indicate the relationship between job satisfaction (dependent variable) with each predictor variables (emotional exhaustion, personal accomplishment, and depersonalization).

The positive value means that the relationship between independent and outcome is positive and vice versa, the result based on the coefficient table above. Thus, there are two predictors indicate negative $b$ values, which is the emotional exhaustion and depersonalization. The negative value showed a negative relationship, whereas when each of the predictors increases, the outcome which is job satisfaction, will decrease. Table 4.7 showed that one predictor has positive $b$ value, which is a personal accomplishment. A positive value indicated a positive relationship where, when personal achievement increases, the outcome also increases. 
Global Business Management Review, 2020

JUNE 2020

http://gbmr.oyagsb.uum.edu.my

There was a significant for each of the independent variables (emotional exhaustion, personal accomplishment and depersonalization) towards the dependent variable (job satisfaction). All the independent variables (emotional exhaustion, personal accomplishment and depersonalization) are significant to the dependent variable. If the Sig. Value is smaller, and $t$ value is more substantial. It will be the highest contribution of the predictor.

From the findings, the highest contributor to job satisfaction is a personal accomplishment with the Sig. value and $t$ value is $t(156)=3.898, \mathrm{p}<0.001$. Then, follow by depersonalization variables' Sig. value and $t$ value is $t(156)=-4.632, \mathrm{p}<0.001$. The last one is emotional exhaustion Sig. value and $t$ value is $t(156)=-3.351, \mathrm{p}<0.05$. Moreover, all these values are less than the alpha value of 0.05. H4 is supported as all the independent variables (emotional exhaustion, personal accomplishment, and depersonalization) significantly influence the dependent variable (job satisfaction).

5.0 Conclusion and Recommendation

Table 5.1: Summary of Research Findings

\begin{tabular}{|c|c|c|c|c|c|}
\hline $\begin{array}{c}\text { Research Objective } \\
\text { (RO) }\end{array}$ & $\begin{array}{c}\text { Research Question } \\
\text { (RQ) }\end{array}$ & $\begin{array}{l}\text { Hypotheses } \\
\text { (H) }\end{array}$ & $\begin{array}{c}\text { Findings } \\
\text { (r-value; } p \text {-value) }\end{array}$ & Conclusior & \\
\hline $\begin{array}{l}\text { R01: To determine } \\
\text { the relationship } \\
\text { between emotional } \\
\text { exhaustion and job } \\
\text { satisfaction }\end{array}$ & $\begin{array}{l}\text { RQ1: Does job burnout } \\
\text { component emotional } \\
\text { exhaustion have a } \\
\text { significant relationship } \\
\text { with job satisfaction? }\end{array}$ & $\begin{array}{l}\text { H1: There is a } \\
\text { significant } \\
\text { relationship } \\
\text { between emotional } \\
\text { exhaustion and job } \\
\text { satisfaction }\end{array}$ & $\begin{array}{l}r \text { value }=-0.379 \\
p \text { value }=0.001\end{array}$ & $\begin{array}{l}\text { The } \mathrm{H} 1 \\
\text { supported }\end{array}$ & \\
\hline $\begin{array}{l}\text { RO2: To examine if } \\
\text { there is relationship } \\
\text { between } \\
\text { depersonalization } \\
\text { and job satisfaction }\end{array}$ & $\begin{array}{l}\text { RQ2: Does job burnout } \\
\text { component personal } \\
\text { accomplishment have a } \\
\text { significant relationship } \\
\text { with job satisfaction? }\end{array}$ & $\begin{array}{l}\text { H2: There is a } \\
\text { significant } \\
\text { relationship } \\
\text { between } \\
\text { depersonalization } \\
\text { and job satisfaction. }\end{array}$ & $\begin{array}{l}r \text { value }=-0.540 \\
p \text { value }=<0.001\end{array}$ & $\begin{array}{l}\text { The H2 } \\
\text { supported }\end{array}$ & \\
\hline $\begin{array}{l}\text { RO3: To determine } \\
\text { relationship } \\
\text { between personal } \\
\text { accomplishment and } \\
\text { job satisfaction }\end{array}$ & $\begin{array}{l}\text { RQ3: Does job burnout } \\
\text { component } \\
\text { depersonalization have } \\
\text { a significant } \\
\text { relationship with job } \\
\text { satisfaction? }\end{array}$ & $\begin{array}{l}\text { H3: There is a } \\
\text { significant } \\
\text { relationship } \\
\text { between personal } \\
\text { accomplishment } \\
\text { and job satisfaction. }\end{array}$ & $\begin{array}{l}r \text { value }=0.381 \\
p \text { value }=<0.001\end{array}$ & $\begin{array}{l}\text { The H3 } \\
\text { supported }\end{array}$ & is \\
\hline $\begin{array}{l}\text { RO4: To evaluate if } \\
\text { there is relationship } \\
\text { between all burnout }\end{array}$ & $\begin{array}{l}\text { RQ4: Does all job } \\
\text { burnout components } \\
\text { have a significant }\end{array}$ & $\begin{array}{l}\text { H4: There is a } \\
\text { significant } \\
\text { relationship }\end{array}$ & $\mathrm{P}$ value $=<0.0001$ & $\begin{array}{l}\text { The H4 } \\
\text { supported }\end{array}$ & is \\
\hline
\end{tabular}


Global Business Management Review, 2020

JUNE 2020

http://gbmr.oyagsb.uum.edu.my

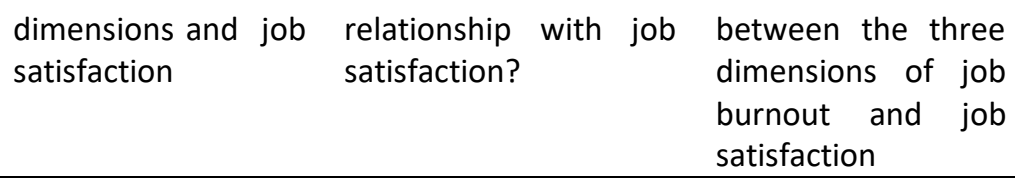

It was indicated that all the job burnout dimensions, namely emotional exhaustion (EE), depersonalization (DP), and personal accomplishment (PA) have a significant relationship with job satisfaction. For emotional exhaustion and depersonalization indicate the negative relationship with job satisfaction where the Pearson correlation coefficient $(r)$ results are $-0.379(\mathrm{EE})$ and 0.540 (DP). It was described, when there is increases in EE or DP, the job satisfaction will decrease.

Personal accomplishment indicates a positive relationship with job satisfaction, with correlation coefficient value 0.381, which is means where there is an increase on PA it also definitely will cause the increases of job satisfaction and vice versa. According to the finding above, the p-value for all the predictors was indicated 0.001 less than a significant alpha value 0.0. So, it can be concluded that all the hypotheses $(\mathrm{H} 1, \mathrm{H} 2, \mathrm{H} 3$, and $\mathrm{H} 4)$ have been supported by the statement. The highest degree correlation is between depersonalization and job satisfaction. This occurs due to many reason including due to severe stress, role and ambiguity and etc.

For future research, besides only focusing on variables of job burnout, adding other or more variables such as organizational commitment, social supports or turnover intention would be good in measuring the challenges and issues faced by the healthcare personnel.

In addition, future researches may study on other recommended professions. Currently, the firefighters and aviation pioneers were on the most stressed jobs reported. Therefore, it is important for future research to focus on this stressful work. Besides conducting a quantitative study, for best results, the future researcher is encouraged to conduct a qualitative study to define and analyse relationship between burnout and job satisfaction among healthcare providers in the northern region. This study can also be used in other areas to compare and contrast at the national level.

It is hoped that this study provides a better understanding, especially to the hospital management in coping with this burnout symptom to help to increase their level of satisfaction. Management 
Global Business Management Review, 2020

JUNE 2020

http://gbmr.oyagsb.uum.edu.my

can set a plan on how to prevent this kind of this situation occurs by providing their staff with counselling session involved with the peer support group. Organizing a program that is related to mental health will allow them on how to cope with the issues. On the other hand, creating a healthy working environment with a positive aura as well empower them in problem-solving, provide effective communication among the superior and co-worker, so that employee felt that they are important and being a part of the organization.

\subsection{References}

Akpinar, A.T., Tas, Y., \& Okur, M.E. (2013). The Effect of Job Satisfaction and Emotional Exhaustion on Affective Commitment of Emergency Services Employees, British Journal of Economics, Finance and Management Sciences, 7 (2), 169-177.

Aziri, B. (2011). Job Satisfaction: A Literature Review, Management Research and Practice, 3(4), 77-86.

BERNAMA. (2019, July 15). Kesesakan di Jabatan Kecemasan hospital kerana kunjungan pesakit melebihi 'level of care'. Kuala LUmpur, Malaysia: Berita Harian Online.

Baldwin, K. D., Barmore, C., Suprina, J. S., \& Weaver, A. (2011). Burnout syndrome in licensed mental health counselors and registered mental health counselor interns: A pilot study. 2011 American Counseling Association Conference, March 26, New Orleans, LA. Retrieved from http://www.counseling.org/Resources

Bazmi, E., Alipour, A., Yasamy, M.T., Kheradmand, A., Salehpour, S., Khodakarim, S., \& Soori, H. (2019). Job Burnout and Related Factors among Health Sector Employees, Iran Journal of Psychiatry, 14(4), 309-316, retrieved on Jan 2020 from https://www.ncbi.nlm.nih.gov/pme/articles/PMC7007511/17.

Burke, R. J., \& Richardsen, A. M. (1996). Stress, burnout, and health. Stress, Medicine, and Health, 101-1 Chan, C. M., Chang, S. M., Chong, Y. S., \& Tang, C. U. (2015). The influence 
Global Business Management Review, 2020

JUNE 2020

http://gbmr.oyagsb.uum.edu.my

of job stress, burnout and job satisfaction among primary school teachers in Ipoh (Doctoral dissertation, UTAR).

Chan, S. H., Wan, Y. K. P., \& Kuok, O. M. (2015). Relationships9-177 among burnout, job satisfaction, and turnover of casino employees in Macau. Journal of Hospitality Marketing \& Management, 24(4), 345-374.

Cordes, C. , \& Dougherty, T.W. (1993). A review and an integration of research on job burnout. Academy of Management Review, 18(4), 621-656.

Freudenberger, H.J. (1974). Staff Burn-Out, Journal of Social Issues, 30(1),159-165, retrieved on January 24, 2020 from https://doi.org/10.1111/j.1540-4560.1974.tb00706.x

Johnson, R.P. (1991). Easing the burden of stress. A stress management program can help eldercare professionals cope, Health Program, 72(1), 56-59, retrieved on January 20, 2020 from https://www.ncbi.nlm.nih.gov/pubmed/10108426

Jing, N.Y. (2019). The 5 Most Stressful Professions in Malaysia 2019, retrieved April 20, 2020 from https://www.jobstore.com/careers-blog/2019/06/21/the-5-most-stressful-professionsin-malaysia-2019/

Farhan. (2015, March 7). S "pore nurse: We are severely overworked \& often don "t even have time for lunch. Singapore News Today. Retrieved October 10, 2019, from http://www.allsingaporestuff.com/article/spore-nurse-we-are-severelyoverworked-often-dont-even-havetime-lunch.

George, J.M., \& Jones, G.R. (2008). Understanding and Managing Organizational behavior, Fifth Edition, Pearson/Prentice Hall, New Yersey, 78.

Hur, W. M., IL Park, S., \& Moon, T. W. (2014). The moderating roles of organizational justice on the relationship between emotional exhaustion and organizational loyalty in airline services. Journal of Services Marketing, 28(3), 195-206. 
Global Business Management Review, 2020

JUNE 2020

http://gbmr.oyagsb.uum.edu.my

Hudek-Knežević, J., Krapić, N., \& Rajter, L. (2005). The relation between emotional control, perceived stress at work and professional burnout in hospital nurses. Psihologijske teme, 14(2.), 41-54.

Janssen, P. P., Schaufelioe, W. B., \& Houkes, I. (1999). Work-related and individual determinants of the three burnout dimensions. Work \& Stress, 13(1), 74-86.

Judge, T. A., \& Church, A. H. (2000). Job satisfaction: Research and practice. In C. L. Cooper \&: E. A Locke (Eds.), Industrial and Organizational Psychology: Linking theory with practice, 166-198, Oxford, UK: Blackwell.

Kuzgun, Y., \& Bacanli, F. (2006). Measurement tools and programme series in psychological counselling and guidance. Ankara: Nobel Press.

Kuzgun, Y. (1999). Vocational counselling: Theory and application. Ankara: Nobel Publishers.

Krejcie, R.V., \& Morgan, D.W. (1970). Determining Sample Size For Research Activities, Educational And Psychological Measurement, 30, 607-610.

Kirk, A. (2015). Nurses at breaking point as number off work with stress soars. Available from: The Guardian https://www.theguardian.com/society/2015/jan/17/nurses-nhs-stressleavestaff-breaking-point [Last Retrieved Octobter 17, 2019].

Lambert, E. G., Qureshi, H., Frank, J., Klahm, C., \& Smith, B. (2018). Job stress, job involvement, job satisfaction, and organizational commitment and their associations with job burnout among Indian police officers: a research note. Journal of Police and Criminal Psychology, $33(2), 85-99$.

Leiter, M. P., \& Schaufeli, W. B. (1996). Consistency of the burnout construct across occupations. Anxiety, stress, and coping, 9(3), 229-243.

Leiter, M. P., Clark, D., \& Durup, J. (1994). Distinct models of burnout and commitment among men and women in the military. The Journal of applied behavioral science, 30(1), 63-82. 
Global Business Management Review, 2020

JUNE 2020

http://gbmr.oyagsb.uum.edu.my

Locke, E. A. (1969). What is job satisfaction? Organizational Behavior and Human Performance, 4, 309-336.

Loh, H. S., Gan, L. Y., Lim, Z. W., Loh, W. S., \& Yong, S. Y. (2016). The relationship between Stress and Job Satisfaction of Nurses in private hospitals of Georgetown, Penang (Doctoral dissertation, UTAR).

Malaysia Investment Development Authority (MIDA). (2019, 10 10). Retrieved from :https://www.mida.gov.my/home/healthcare-sector/posts/

Maslach, C., Jackson, S. E., \& Leiter, M. P. (1996). Maslach Burnout Inventory manual (3rd ed.). Palo Alto, CA: Consulting Psychologists Press.

Maslach, C. (2003). The Burnout: The Cost of Caring. Cambridge, MA: Malor Boo

Maslach, C., Schaufeli, W. B., \& Leiter, M. P. (2001). Job burnout. Annual Review of Psychology, $52,397-422$.

Maslach, C., \& Leiter, M.P. (2016). Understanding the burnout experience: recent research and its implications for psychiatry, World Psychiatry, 15(2), 103-111.

Morse, G., Salyers, M. P ., Rollin's, A. L., Monroe DeVita, M., \& Pfahler, C. (2012). Burnout in mental health services: a review of the problem and its remediation. Administration and Policy in Mental Health, 39 (2), 341-352. doi:10.1007/s10488-011-0352-1

Mäkikangas, A., \& Kinnunen, U. (2016). The person-oriented approach to burnout: A systematic review, Burnout Research, 3 (1), 11-23, retrieved on January 23, 2020 from https://www.sciencedirect.com/science/article/pii/S2213058615300127

Meyer, J.P., Allen, N.J. ,\& Smith, C.A. (1993). Commitment to organisations and occupations: Extension and test of a three-component conceptualization. Journal of Applied Psychology, 78(4), 538-551. 
Global Business Management Review, 2020

JUNE 2020

http://gbmr.oyagsb.uum.edu.my

Miao, C., Humphrey, R. H., \& Qian, S. (2016). Leader emotional intelligence and subordinate job satisfaction: A meta-analysis of main, mediator, and moderator effects. Personality and Individual Differences, 102, 13-24.

Nagar, K. (2012). Organizational Commitment and Job Satisfaction Among Teachers During Times of Burnout, VIKALPA, 37(2), 43-60.

Piko, B. F. (2006). Burnout, role conflict, job satisfaction and psychosocial health among Hungarian health care staff: A questionnaire survey. International Journal of Nursing Studies, 43(3), 311-318.

Pillay, R. (2009), Work satisfaction of professional nurses in South Africa. A comparative analysis of the public and private sectors. Human Resources for Health, 7(15), 1-10.

Portoghese,I., Rosa, M.G. , Gabriele, C.C., \& Campagna, F.M. (2014). Burnout and Workload Among Health Care Workers: The Moderating Role of Job Control, Safety and Health at Work, 5 (3), 152-157, retrieved on January 20, 2020 from https://doi.org/10.1016/j.shaw.2014.05.004

Salanova, M., Llorens, S., García-Renedo, M., Burriel, R., BresÓ, E., \& Schaufeli, W. B. (2005). Towards a four-dimensional model of burnout: A multigroup factor-analytic study including depersonalization and cynicism. Educational and Psychological Measurement, 65(5), 807819.

Schaufeli, W.B., Leiter, M.P., Maslach, C., Jackson, S.E. (1996). The MBI-General Survey, from C. Maslach, S.E. Jackson, M.P. Leiter (Eds.), Maslach Burnout Inventory manual (3rd ed.), Consulting Psychologists Press.

Sekaran, U., \& Bougie, R. (2012). Research methods for business: A skill building approach (6th ed.). Chichester, West Sussex: John Wiley \& Sons, Inc.

Shah, A. (2018, August 26). [EXCLUSIVE] Over 2,000 suicide cases in the past four years (NSTTV). Retrieved October 25, 2019, from New Straits TImes: 
Global Business Management Review, 2020

JUNE 2020

http://gbmr.oyagsb.uum.edu.my

https://www.nst.com.my/news/exclusive/2018/08/404930/exclusive-over-2000-suicidecases-past-four-years-nsttv

Tourigny, L. , Baba, V.V., \& Wang, X. (2010). Burnout and depression among nurses in Japan and China: the moderating effects of job satisfaction and absence, The International Journal of Human Resource Management , 21 (10). 2741-2761, https://doi.org/10.1080/09585192.2010.528656

Tarcan, G. Y., Tarcan, M., \& Top, M. (2017). An analysis of relationship between burnout and job satisfaction among emergency health professionals. Total Quality Management \& Business Excellence, 28(11-12), 1339-1356.

The, Lancet. (2017). Suicide among healthcare workers: time to act. Lancet (London, England), 389(10064), 2.

The Star Online. (2018, December 4). Malaysia's healthcare market to reach RM217.9b by 2027, says Fitch Research. Kuala Lumpur, Wilayah Persekutuan, Malaysia: The Star.

Van Mol, M. M., Kompanje, E. J., Benoit, D. D., Bakker, J., \& Nijkamp, M. D. (2015). The prevalence of compassion fatigue and burnout among healthcare professionals in intensive care units: a systematic review. PloS one, 10(8), e0136955.

Wright, T. A., \& Cropanzano, R. (1998). Emotional exhaustion as a predictor of job performance and voluntary turnover. Journal of Applied Psychology, 83(3), 486.

WHO (2017). Protecting workers' health, World Health Organisation, retrieved on January 2, 2020 from https://www.who.int/news-room/fact-sheets/detail/protecting-workers'-health

WHO (2019). Burnout an "occupational phenomenon": International Classification of Diseases, Mental health, World Health Organisation, retrieved on January 2, 2020, https://www.who.int/mental_health/evidence/burn-out/en/

Ullström, S., Sachs, M. A., Hansson, J., Øvretveit, J., \& Brommels, M. (2014). Suffering in silence: a qualitative study of second victims of adverse events. BMJ Qual Saf, 23(4), 325-331. 
Global Business Management Review, 2020

JUNE 2020

http://gbmr.oyagsb.uum.edu.my

Wardle, E.A., \& Mayorga, M.G. (2016). Burnout Among The Counselling Profession: A Survey Of Future Professional Counsellors, I-Manager's Journal o Educational Psychology, 10 (1), 9-16. 